\title{
The Relationship between International Students' Social Skills, Social Support Networks and Adaptation in Japan
}

\author{
Shaoyu Ye
}

\begin{abstract}
Previous studies have suggested that international students' (IS) social support networks (SSN) including more different-language speakers, especially Japanese native speakers, would be helpful in decreasing their maladaptation through face-to-face (FTF) communication. This study investigates the effect of social skills on ISs' intercultural adaptation, considering the mediations of SSNs formed through voice calls, text messages via instant messaging (IM) and traditional email, comparing to those via FTF. This study conducted a two-wave panel survey and an analysis of cross-lagged effect model based on 99 ISs' responses. As a result, it was found that (a) female ISs' SSNs with different-language speakers through FTF helped decrease their maladaptation, (b) both male and female ISs with lower levels of maladaptation were able to communicate with more different-language speakers through FTF interactions, and (c) female ISs' social skills had positive effects on their SSNs with cross-gender/ different-language speakers via email. Implications were discussed based on these results.
\end{abstract}

Index Terms-International students in Japan, communication media, social support networks, maladaptation, panel survey.

\section{INTRODUCTION}

In the last two decades, the number of non-native Japanese residents in Japan has increased dramatically. In July 2008, the Japanese government published a policy stating that Japan aims to accept 300,000 ISs by 2020 [1]. Therefore, as of May 1, 2015, there are 208,379 ISs in Japan [2], which is twice the number of the last decade. As more and more ISs will come to study in Japan, improving their adaptation is extremely important to their intercultural communication with Japanese people to adapt in the Japanese society and make contributions to their own careers in the future.

However, it is pointed out that the most stressful problems for ISs in Japan are their relationship with Japanese people and their acquisition of the Japanese language and its usage [3]. This is still the most difficult part, even when they are satisfied with their life in Japan overall [4]. In particular, communication with Japanese people and understanding their way of thinking are the most difficult aspects for ISs [5]. Therefore, [6], [7] suggested that increasing ISs' communication with hosts would be an effective way to solve this problem. In other words, if ISs are able to form stable and fruitful relationships with Japanese people, they will gain various supports such as coping with stress and improving

Manuscript received January 19, 2017; revised March 24, 2017. This study was supported by JSPS KAKENHI Grant Number 14J11782.

Shaoyu Ye is with the faculty of Library, Information and Media Science, University of Tsukuba, 3058550 Japan (e-mail: shaoyu@ slis.tsukuba.ac.jp). adaptation. These beneficial relationships are known as "social support networks" (SSN). SSN is a general psychological term that indicates personal relationships expected to provide both tangible and intangible support and to promote intercultural adaptation [8]. Studies suggest that including more Japanese people in their SSNs will help ISs acquire Japanese style social skills, and therefore, improve their intercultural adaptation. However, the above findings were based on face-to-face (FTF) interactions because people did not use computers or mobile phones, smartphones, etc. to communicate at that time. In Japan, before smartphones became prevalent, regular cell phones had been widely used since 1999 not only as traditional telephones but also to access the Internet and to send and receive text messages, including short message service (SMS). However, the regular cell phones in Japan at that time only supported typing in Japanese or English, which may have hindered text communication for some ISs. Therefore, ISs used cell phones to make voice calls to their friends, especially those who came from the same countries, rather than sending text messages to Japanese people [9]. In Japan, over $90 \%$ of the ISs are Asian students, and over 70\% are Chinese and Korean students [2], so making phone calls with other ISs from the same countries means that ISs form in-group communities without intercultural contacts. Therefore, [9] indicates that from the viewpoint of better understanding the Japanese culture and acquiring the Japanese language, cell phone usage inhibits ISs' communication with Japanese people and, therefore, inhibits their adaptation.

In Japan, smartphones have become the most popular mobile devices. Since late June 2011, the application LINE has been imported to Japan and has become prevalent in a short time. In fact, [10] conducted a survey in early-mid June 2011, in which the possession rate of smartphones was nearly $10 \%$ overall, to investigate how ISs' usage of computers (email and Internet accessing) and cell phone/smartphone (text messages, voice calls and Internet accessing) influence their adaptation situations. They found that there is a significant relationship between ISs' communication media usage and adaptation situations, with cell phone usage having a particularly positive effect on their improvement of adaptation situations, which was larger than that of computer usage. However, issues such as the types of social support they receive from different SSNs through communication media still remain unknown.

Smartphone usage, along with various media usage, has changed people's communication behaviors more dramatically than ever before. For instance, it was found that high school students in Belgium and adults in South Korea form more intimate relationships by sending text messages/ 
making phone calls via various instant messaging (IM) applications, and by sending emails and other messages based on FTF interactions, than by relying only on FTF interactions [11], [12]. Additionally, young Americans and Japanese send emails to their academic advisors and faculty members in their universities to form formal relationships, while sending text messages via IM to their friends for informal relationships [13], [14]. These facts allow us to assume that ISs also may send email to their academic advisors and faculty members for formal relationships, while using IM to send text messages to their intimate friends for private relationships.

Regarding the effects of social networks on users' communication, [15] conducted two surveys targeting Japanese natives to examine the effects of social networks through FTF and computer-mediated communication (CMC) on reducing loneliness. As a result, he found that the effect of social skills on loneliness was mediated by their social network through FTF directly, whereas no similar effects were detected for the CMC with existing friends or strangers. He suggested that people may receive emotional support from FTF social networks but form social networks through CMC for other purposes such as information exchange and so on. The effects of Japanese local people's social networks on decreasing loneliness might differ from ISs' social networks on adaptation; however, it is possible that ISs receive different supports from different social networks. Therefore, this study investigates ISs' SSNs formed through FTF, voice calls, and text messages through IM and traditional emails, and examines their relationships with each other.

Up until now, "intercultural adaptation” has had different definitions and constitution scales in different studies. Tanaka et al. conducted a survey to clarify the constitution scales of ISs' adaptation and the relationships of those scales with social support in Japan [16]. As a result, four factors were detected, namely, "general maladaptation," "selfcontrol adaptation," "affinity adaptation” and "dependence adaptation.” Here, "general maladaptation” refers to feelings of interpersonal stress and daily life stress, as well as loneliness; "self-control adaptation" refers to coping with stress and health problems by themselves; "affinity adaptation” refers to ISs' satisfaction with others, as well as their mental and physical health; and "dependence adaptation" refers to coping with dependent stress and adaptation such as Japanese language learning and its usage and culture understanding. References [6], [7] investigated ISs' configurations of SSNs and their relationships with their adaptation. As a result, it was found that the average number of ISs' SSNs was 7.76 (the maximum number was 10), among which $53.4 \%$ were Japanese people; however, it was found that ISs' received supports had correlations with some of their adaptations but had no correlation with their general maladaptation. Additionally, those ISs with higher levels of social skills were able to develop larger SSNs that had positive correlation with their adaptation. In fact, [17] suggests that social skills may have more important effects than language ability on ISs' intercultural adaptation since most of the ISs' stress resulted from their unfamiliarity with interpersonal behaviors in a new culture. However, the above findings only indicated correlation but did not show any causal relationship. Social skills have effects on decreasing loneliness through the mediation effects of social networks through FTF directly, but no similar mediating effects for CMC were detected [15]. Considering that ISs make voice calls and send text messages through IM to same-language speakers, while interacting with different-language speakers through FTF and email [18], social skills may have fewer effects on their SSNs through voice calls and IM usage.

Furthermore, [19] conducted a panel survey to examine the relationship between Chinese students' received support and their adaptation in Japan, in which Time 1 was three months after coming to Japan, and Time 2 and Time 3 were nine months and one year and nine months, respectively. As a result, it was found that (a) their received support had positive effects on improving adaptation in Time 1 , and these two factors and the received support in Time 2 had positive effects on improving adaptation in Time 2; and (b) the received supports and their adaptation in both Time 1 and Time 2 had positive effects on improvement of adaptation in Time 3. Receiving more social supports means that ISs have meaningful SSNs; meanwhile, improving adaptation allows them to communicate and form stable relationships with others, which offers ISs various supports in turn. Currently, people use communication media to form different SSNs regardless of physical distance, and different social networks may offer different supports; therefore, this study investigates whether the same causal relationship will exist or not in terms of SSNs through communication media.

Finally, it has been observed that there are differences between males and females in their communication and media usage [20]. For instance, [21] indicated that compared to male students, female students have higher levels of social anxiety, which leads them to talk with others online more (especially via IM) and to feel more comfortable using only text messages via SNS. Furthermore, [22] indicated that female Japanese students tend to be more active than male students in forming larger and more intimate social networks by sending more text messages via cell phones, and the same results were reported in terms of IM text message usage in other countries [23]. Additionally, compared to males, females tend to feel lonelier [24], and thus make more selfdisclosure to others both FTF and online [25]. In general, females feel happier if they are satisfied with their relationship with male people [26], and females tend to adapt better in terms of language learning in new environments whereas males tend to adapt better in coping with heath and weather problems [27]. Furthermore, compared to females, males are more reluctant to ask for help from the same gender [28]. On the basis of these, it is reasonable to believe that females will be more active in using communication media to develop SSNs with different people, especially with crossgender people and, therefore, will be able to adapt better than males.

In sum, based on the above discussions, this study examines the following three hypotheses. As it is common for ISs to make voice calls and send text messages to their families and friends who are in their home countries, SSNs in this study also include those who live abroad. Additionally, intercultural adaptation refers to "general maladaptation" in this study since it relates to intercultural contacts with others 
and is expected to be decreased through meaningful SSNs.

H1: Female students will be able to form SSNs with others, especially with cross-gender people, which will be helpful in decreasing their maladaptation.

$\underline{\text { H2}}$ : Students with lower levels of maladaptation will be able to communicate with different-language speakers through FTF and communication media usage, whereas students with higher levels of maladaptation might tend to communicate with same-language speakers more, regardless of communication media, among which gender differences will be found.

H3: Social skills will have greater effects on SSNs through FTF interactions than voice calls, text messages through IM and traditional emails.

\section{METHOD}

\section{A. Panel Survey}

To examine the above, a two-wave panel survey was conducted that allowed for repeated observations over time of a set of variables for the same sample units. The targets were ISs enrolled at national universities in the Kanto Region, Japan. The survey was first conducted in July 2014 (T1) and then again in December 2014 (T2). There were 142 submitted responses in $\mathrm{T} 1$, of whom 138 became the analyzed targets who were asked to participate in T2. However, only 103 submitted their responses in T2. As a result, 99 became the analyzed targets.

The survey included three parts-Part A, Part B and Part $\mathrm{C}$ - with the content in each part as follows.

Part A gathered their personal information including demographic data (e.g., gender, age, academic standing and nationality), their period of staying in Japan, their learning history of the Japanese language and their Japanese language abilities (score and level of Japanese Language Proficiency Test ${ }^{1}$; self-evaluation of their Japanese language proficiency in reading, listening, speaking, and writing compared with an adult Japanese native speaker in percentage) and English language abilities (e.g., score of TOEFL-iBT, TOEIC; selfevaluation of their English language proficiency in reading, listening, speaking, and writing compared with an adult English native speaker in percentage), living situation, experience with/frequency of doing part-time jobs, and so on (see Table I). Additionally, 10 items were used to measure ISs' social skills (Table II). Originally, this scale was developed for Chinese students based on the KiSS-18 [29]. As over $60 \%$ of the ISs are Chinese students in Japan [2], it is believed that this scale would be suitable to measure ISs' social skills. Therefore, some expressions were revised so that they could be used to measure general ISs. The respondents were asked to rate the scale using a 5-point scale (“5. Strongly agree”; “3. Neither”; “1. Strongly disagree”).

Part B measured ISs’ use of media, including possession

\footnotetext{
${ }^{1}$ The Japanese Language Proficiency Test (JLPT) measures Japanese non-native speakers' linguistic competence in listening and reading Japanese. JLPT had 4 levels before 2010; Level 1 was the highest while Level 5 was the lowest. Since 2010, JLPT revised to 5 levels, N1-N5. N1 and N2 are approximately the same levels as Level 1 and Level 2, N4 and N5 are
}

rate of regular cell phones/smartphones and computers, and their daily accessing time of the Internet via these devices measured by a 7-point scale ("7. Over 6 hours"; "4. 3-4 hours"; "1. Less than 1 hour"). This part also gathered information about their configurations of SSNs through FTF, voice calls, IM text messages and traditional emails. Before going to each SSN, the ISs were asked to answer the number of "Japanese friends/acquaintances with whom I have frequent contact in Japan," "Friends/acquaintances from my home country with whom I have frequent contact in Japan," and "Friends/acquaintances living in my home country with whom I have frequent contact," by rating on a 7-point scale (“7. Over 25 persons”; “4. 10-15 persons”; “1. None”).

Following the definition in [3] [6] [7], this study defined the "SSNs" as "important relationships in their daily lives" and asked the ISs to list UP TO 10 people they had met in person, made voice calls to, or sent IM messages or emails to in the previous six months for important conversations. Here, "voice calls" includes both calls from regular cell phones/smartphones (iPhone/Android) and those through applications, and "IM" refers to "text messages sent via instant messaging from regular cell phones/smartphones (iPhone/Android)/computers such as LINE, Skype, Facebook, Yahoo, and so on.” For each SSN, ISs were asked to provide their contact person's gender, age, language used when communicating, place of residence, relationship, and frequency of contact (from " 4 . Almost every day” to " 1 . Less than once per month"), as well as the main content of the communication and importance of the person in their lives (“5. Very important”; “3. Moderately important”; “1. Not important at all”). Additionally, the ISs were asked to answer whether the person(s) listed in the SSNs via voice calls/ IM/email was/were also listed in those via FTF, and so on.

Part C measured ISs' general maladaptation symptom, namely, feelings of interpersonal stress, loneliness and feelings of daily life stress, which were chosen from [6] and [10]. The respondents were asked to rate all these items using a 5-point scale (“5. Strongly agree”; "3. Neither”; "1. Strongly disagree”; Tables II-V).

Additionally, to avoid any influence of the ISs' Japanese language abilities on their responses, the questionnaire was prepared in Japanese, English, Chinese and Korean versions. The translation accuracy was confirmed by translating back into Japanese from the other three languages. The ISs were free to choose any of these language versions. Before distribution, we conducted a preliminary survey to confirm its reliability, in which 6 ISs offered their cooperation. Based on their comments, we made some minor revisions accordingly.

\section{B. Analysis of the Causal Relationships}

Conceptual Model. This study employed the model as Fig. 1 shows to examine the causal relationships between ISs' social skills, SSNs and maladaptation, and compared them among their SSNs formed through FTF, voice calls, IMs and emails. The model investigated whether social skills help form SSNs with different-language speakers (path $a$ ), and whether such SSNs would be helpful in decreasing their

approximately the same levels as Level 3 and Level 4, whereas N3 is positioned at a level bridging the old Level 2 and Level 3. 
maladaptation (path $b$ ) or social skills would have a direct effect on their maladaptation or not (path c).

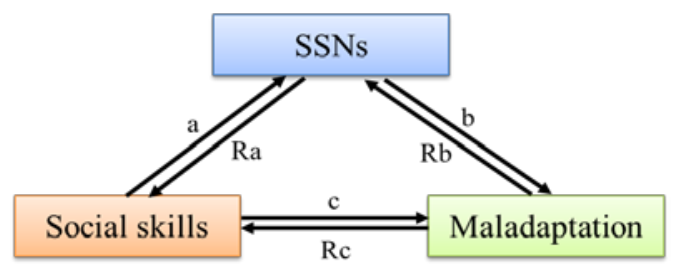

Fig. 1. Conceptual model in this study.

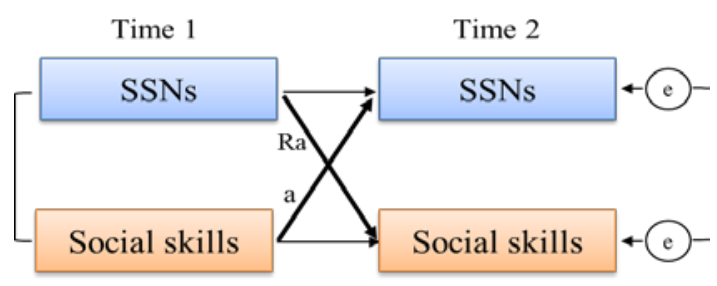

Fig. 2. Two-variable model in this study.

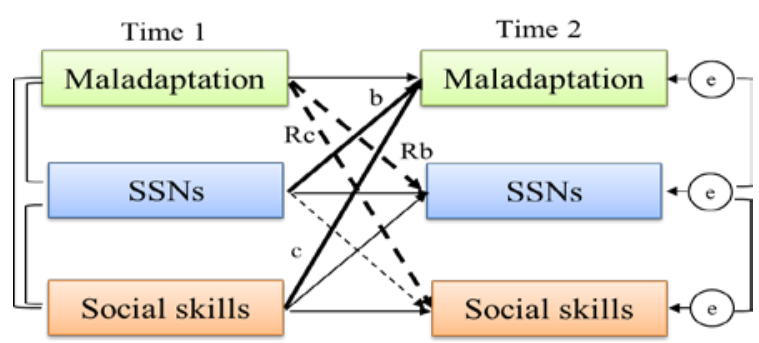

Fig. 3. Three-variable model in this study.

Analysis Model. To examine the conceptual model shown in Fig. 1, a covariance structure analysis was conducted using the "cross-lagged effect model." This model has wide applicability for panel analysis. When a change in the dependent variables is modeled according to a discrete time process, the cross-lagged model is appropriate whenever the causal lags are approximately equal to the time period between measurements. When changes in the dependent variables continuously occur, the cross-lagged model can be used to determine an integral solution to a system of differential equations in which the instantaneous rates of change in the two variables are dependent on one another over time [30]. Additionally, the analyses were conducted over two steps based on the cross-lagged effects model using two-wave panel data to examine the three variables' relationships. In particular, the model shown in Fig. 2 was employed to examine path $a$, and Fig. 3 was used to examine paths $b$ and $c$. Here, path $a$ in Fig. 2, and paths $b$ and $c$ in Fig. 3 , refer to paths $a, b$, and $c$ in Fig. 1, respectively. The reason for dividing the analysis into two steps is that there might be problems when analyzing path $a$ in the three-variable model (Fig. 3). As Fig. 1 shows, theoretically, path $a$ goes from an independent variable to a mediator and occurs earlier than path $b$. In other words, path $a$ was not expected to be affected by the dependent variable. However, if the three-variable model was conducted at the same time, the effects from the dependent variable on path $a$ might be counted. It is desirable to examine the three-variable model using a three-wave panel survey, in order to ease the problem when using two-wave panel data; the present study followed the way of [31] and [32] and conducted analysis by separating path $a$ as Fig. 2 shows, while paths $b$ and $c$ were examined in Fig. 3.

This study also examined the opposite path directions to clarify the factors that influenced the ISs' social skills (path $R a$ ); path $R b$ examined the effects of maladaptation on SSNs, and path $R c$ examined the effects of maladaptation on social skills. If path $R a$ and/or $R c$ are significant, that indicates that SSNs/adaptation influence their social skills. If $R b$ is significant, that means that adaptation influences their SSNs. In this study, $R a$ was examined as for path a by using the model in Fig. 2, while $R b$ and $R c$ were examined with path $b$ and path $c$ using the model in Fig. 3 .

\section{RESULTS}

\section{A. Descriptive Results}

For details regarding demographics of the 99 ISs, see Table I. Over $70 \%$ of the 99 ISs were graduate students, which is the same as JASSO's results. Additionally, except for the Philippines, the other top four nationalities in this study were the 1, 6, 7 and 9 in JASSO's results, which suggests that the analyzed participants in this study generally reflected the distribution as the nationwide survey indicates. On the other hand, over $70 \%$ received scholarship, and $43.4 \%$ were from MEXT, and this percentage was higher than the nationwide survey's [2]. Table I also showed that the possession rates of smartphones and computers among ISs were extremely high.

TABLE I: INFORMATION FOR ANALYZED STUDENTS

\begin{tabular}{|c|c|}
\hline Gender ratio & Males: 59 (59.6\%); $\quad$ Female: $40(40.4 \%)$ \\
\hline Age (in years) & $26.6(S D=3.37 ;$ range: $19-38$ years $)$ \\
\hline Academic standing: & $\begin{array}{l}\text { Undergraduate: } 8.1 \% \text {; Master course: } 39.4 \% \\
\text { Ph.D. course: } 35.4 \% \text {; } \\
\text { Research students: } 12.1 \% \\
\text { Others: } 5.1 \%\end{array}$ \\
\hline $\begin{array}{l}\text { Nationalities } \\
\text { (Top 5) }\end{array}$ & $\begin{array}{l}\text { Chinese: } 42.4 \% \text {; } \\
\text { Thailand: } 7.1 \% \text {; } \\
\text { Malaysia: } 5.1 \%\end{array}$ \\
\hline $\begin{array}{l}\text { History of stay in } \\
\text { Japan: }\end{array}$ & 34.3 months ( $S D=24.5$, range: $3-118$ months) \\
\hline $\begin{array}{l}\text { History of learning } \\
\text { the Japanese }\end{array}$ & 37.9 months ( $S D=35.1$, range: $2-165$ months) \\
\hline JLPT-N1/L1 holder & $39.4 \%$ \\
\hline $\begin{array}{l}\text { English language } \\
\text { abilities }^{2}\end{array}$ & $\begin{array}{l}\text { TOEFL-iBT: } 32.3 \% \text { (score range: } 60-116 \text { ) } \\
\text { TOEIC: } 45.5 \% \text { (score range: } 553-990 \text { ) } \\
\text { TOEFL-iBT \& TOEIC: } 1.0 \% \\
\text { IELTS: } 5.1 \% \\
\text { Not take any: } 17.2 \%\end{array}$ \\
\hline Living situation & $\begin{array}{l}\text { Alone: } 52.5 \% \\
\text { With other ISs: } 32.3 \% \\
\text { With a family: } 9.1 \% \text {; } \\
\text { With Japanese students: } 2.0 \% \\
\text { Other: } 4.0 \%\end{array}$ \\
\hline Scholarship & $\begin{array}{l}\text { Yes: } 72.7 \% \text { (MEXT: } 43.4 \% \text {; } \\
\text { Private foundations in Japan: } 22.2 \% \\
\text { Their own government: } 7.1 \% \text { ) }\end{array}$ \\
\hline Part-time job daily & Yes: 31.3\%; \\
\hline $\begin{array}{l}\text { Possession of } \\
\text { mobile devices }\end{array}$ & $\begin{array}{l}\text { Cell phones: }(5.1 \%) ; \quad \text { iPhones: } 71.7 \% \\
\text { Androids: } 22.2 \% ; \quad \text { Cell phone \& iPhone: } 1.0 \%\end{array}$ \\
\hline $\begin{array}{l}\text { Possession of } \\
\text { computers }\end{array}$ & Yes: $96.0 \%$ \\
\hline
\end{tabular}

${ }^{2}$ Since TOEFL and TOEIC have different standards, in this study, ISs' English ability was calculated as below. (a) For ISs who had TOEIC over 951: TOEIC score $/ 10+8$, for those $901-905$ : TOEIC score $/ 10+4$, for those 851-900: TOEIC score/10 + 3, and so on. (b) For those did not take any tests, it was calculated as: (self-evaluation percentage of "listening" + "speaking" + "reading” + “writing”)/ 400. 
Next, a $t$-test (independent sample) was conducted to confirm whether there is any gender difference in their language abilities, history of stay in Japan or history of learning the Japanese language. ${ }^{3}$ As a result, significant differences in their history of learning the Japanese language were found (males vs. females: 31.6 vs. $42.3, t(96)=2.17$, $p<.05)$.

\section{B. Internal Reliability for Each Scale}

Tables II through V show the items and average score for social skills, feelings of interpersonal stress, loneliness and feelings of daily life stress, respectively. From the results, we can see that their social skills were high overall since all of the scores were higher than the median score of 3.00 . Additionally, it can be found that their level of feelings of interpersonal stress was higher than their loneliness and stress of daily life. Next, we confirmed each scale's internal reliability by calculating its Cronbach's $\alpha$ coefficients. As a result, the coefficients for each scale show high reliabilities. Since the internal reliabilities were high, this study used the total score of each scale to analyze in the following analysis. Before conducting the causal relationship analysis, this study conducted a $t$-test to confirm whether there was any difference due to gender, but no effects for gender were detected among all these factors. As "maladaptation" is a concept variable which consists of observed variables, namely, feelings of interpersonal stress, loneliness and feelings of daily life stress, this study calculated the three scales' total scores as the score of maladaptation in the following analysis. Compared to $\mathrm{T} 1$, there were significant changes in T2's maladaptation (T1 vs. T2: 66.84 vs. 54.97, $t(98)=8.77, p<.001)$. This meant that ISs felt less stressful towards interpersonal relationships and daily life, and decreased loneliness with time changes.

TABLE II: ITEMS AND AVERAGE SCORES FOR SOCIAL SKILLS

\begin{tabular}{|c|c|c|}
\hline Items & $\mathrm{M}(\mathrm{T} 1)$ & $\mathrm{M}(\mathrm{T} 2)$ \\
\hline $\begin{array}{l}\text { 1. I am good at giving easy-to-follow instructions to } \\
\text { other people so that they know what to do. }\end{array}$ & 3.68 & 3.70 \\
\hline 2. I am able to appease people when they are angry. & 3.29 & 3.38 \\
\hline $\begin{array}{l}\text { 3. I am able to have a conversation immediately with } \\
\text { someone, even with people I don't know well. }\end{array}$ & 3.39 & 3.47 \\
\hline $\begin{array}{l}\text { 4. I am able to deal with people even if there is some } \\
\text { tension between us. }\end{array}$ & 3.41 & 3.49 \\
\hline $\begin{array}{l}\text { 5. I am able to decide what I should do and how I } \\
\text { should work. }\end{array}$ & 3.82 & 3.74 \\
\hline $\begin{array}{l}\text { 6. I am able to discover problems immediately when } \\
\text { working. }\end{array}$ & 3.73 & 3.70 \\
\hline $\begin{array}{l}\text { 7. I am able to process information from different } \\
\text { sources even from ones with opposing } \\
\text { perspectives. }\end{array}$ & 3.71 & 3.69 \\
\hline $\begin{array}{l}\text { 8. I am good at introducing myself to people whom I } \\
\text { meet for the first time. }\end{array}$ & 3.47 & 3.57 \\
\hline $\begin{array}{l}\text { 9. I am able to apologize immediately when I make a } \\
\text { mistake. }\end{array}$ & 3.89 & 3.91 \\
\hline $\begin{array}{l}\text { 10. I am able to get along well with people even if } \\
\text { our opinions are different. }\end{array}$ & 3.77 & 3.79 \\
\hline
\end{tabular}

${ }^{3}$ Japanese Language Proficiency was calculated as follows. (a) For ISs who had passed JLPT-L1/N1, it was calculated as L1 score/400 or N1 score/180 (The total score of L1 is 400 while N1 is 180); (b) For ISs who had passed JLPT-L2/N2, L2 score/400 x .08 or N2 score/180 x .08 (L2/N2's level is approximately $80 \%$ of L1/N1's); (c) For ISs who did not take JLPT, it was calculated as: (self-evaluation percentage of "listening" + "speaking” + "reading” + "writing”)/400.
TABLE III: ITEMS AND AVERAGE SCORES FOR FEELINGS OF INTERPERSONAL STRESS

\begin{tabular}{|c|c|c|}
\hline Items & $\mathrm{M}(\mathrm{T} 1)$ & $\mathrm{M}(\mathrm{T} 2)$ \\
\hline $\begin{array}{l}\text { 1. Understanding the real meaning of Japanese people } \\
\text { given the ambiguity of many expressions in } \\
\text { Japanese. }\end{array}$ & 3.11 & 3.05 \\
\hline $\begin{array}{l}\text { 2. Being disregarded even when I try to ask Japanese } \\
\text { people questions or want to join their discussions. }\end{array}$ & 2.64 & 2.68 \\
\hline 3. Making close relationships with Japanese students. & 3.10 & 3.13 \\
\hline 4. Being treated "special” because I am a foreigner. & 2.92 & 3.05 \\
\hline $\begin{array}{l}\text { 5. Always having to be courteous by saying } \\
\text { "sumimasen" "arigato" etc. }\end{array}$ & 2.18 & 2.31 \\
\hline $\begin{array}{l}\text { 6. Gathering information necessary for daily life from } \\
\text { Japanese people. }\end{array}$ & 2.69 & 2.56 \\
\hline $\begin{array}{l}\text { 7. Feeling that there is a discrepancy between topics of } \\
\text { interest to Japanese people and what I find } \\
\text { interesting. }\end{array}$ & 2.79 & 2.99 \\
\hline 8. Not having a chance to learn the Japanese language. & 2.48 & 2.55 \\
\hline 9. Having to work in order to live here. & 2.46 & 2.67 \\
\hline $\begin{array}{l}\text { 10. Experiencing Japanese people’s cold attitudes with } \\
\text { regard to interpersonal relationships. }\end{array}$ & 2.81 & 2.95 \\
\hline$\alpha=.81(\mathrm{~T} 1) ; \alpha=.78(\mathrm{~T} 2)$ & & \\
\hline
\end{tabular}

TABLE IV: ITEMS AND AVERAGE SCORES FOR LONELINESS

\begin{tabular}{lcc}
\hline \multicolumn{1}{c}{ Items } & $\mathrm{M}(\mathrm{T} 1)$ & $\mathrm{M}(\mathrm{T} 2)$ \\
\hline 1. There is little interaction with other people. & 2.48 & 2.04 \\
2. There is no one that I can count on. & 2.13 & 1.92 \\
3. I am not close to anyone. & 1.98 & 1.95 \\
4. I feel that I do not belong to any group. & 2.07 & 1.93 \\
5. I feel miserable due to my shyness. & 1.89 & 1.79 \\
6. I have acquaintances, but I do not have close friends. & 2.03 & 2.04 \\
\hline$\alpha=.85(\mathrm{~T} 1) ; \alpha=.91(\mathrm{~T} 2)$ & & \\
\hline \hline
\end{tabular}

TABLE V: ITEMS AND AVERAGE SCORES FOR STRESS OF DAILY LIVES

\begin{tabular}{|c|c|c|}
\hline Items & $\mathrm{M}(\mathrm{T} 1)$ & $\mathrm{M}(\mathrm{T} 2)$ \\
\hline $\begin{array}{l}\text { 1. I have no confidence to continue doing research or } \\
\text { study at university. }\end{array}$ & 1.99 & 2.09 \\
\hline $\begin{array}{l}\text { 2. I always feel uncomfortable, because I do not know } \\
\text { Japanese greetings/manners. }\end{array}$ & 2.29 & 2.26 \\
\hline $\begin{array}{l}\text { 3. I cannot talk to faculty members/administrative staff } \\
\text { freely at the university. }\end{array}$ & 2.51 & 2.64 \\
\hline $\begin{array}{l}\text { 4. I find it difficult to understand and adapt to cultural } \\
\text { norms in Japan when interacting with Japanese } \\
\text { people and Japan society. }\end{array}$ & 2.56 & 2.33 \\
\hline $\begin{array}{l}\text { 5. I am not enjoying studying or doing research at this } \\
\text { university. }\end{array}$ & 2.04 & 2.19 \\
\hline $\begin{array}{l}\text { 6. I always feel that my behavior is limited, because I } \\
\text { am a foreigner. }\end{array}$ & 2.68 & 2.65 \\
\hline 7. My emotions change drastically. & 2.38 & 2.38 \\
\hline $\begin{array}{l}\text { 8. I am not able to make a presentation/discussion in } \\
\text { Japanese or English during classes in my specialty. }\end{array}$ & 2.06 & 1.91 \\
\hline $\begin{array}{l}\text { 9. I have no international students or Japanese students } \\
\text { with whom I can talk about anything. }\end{array}$ & 1.80 & 1.93 \\
\hline 10. I frequently feel homesick. & 2.17 & 2.09 \\
\hline 11. I do not feel like studying very much. & 2.27 & 2.36 \\
\hline 12. I have financial problems. & 2.32 & 2.36 \\
\hline
\end{tabular}

\section{Configurations of Each SSN and Their Relationships}

Prior to examining the relationship between ISs' social skills, SSNs and adaptation, it is necessary to investigate the configurations of each SSN. Table IV shows the average number of people in each SSN and their relationships. As mentioned earlier, the respondents were asked to list up to 10 persons for important conversations in the last six months, so the maximum number for each SSN is 10 . In order to clarify SSN effects, this study divided the contact persons into 
"same language” and "different language”; the former refers to those from the same countries, while the latter refers to Japanese people and other ISs from other places.

TABLE VI: CONFIGURATIONS OF ISS \& SSNS AND THEIR RELATIONSHIPS

\begin{tabular}{|c|c|c|c|c|c|c|}
\hline \multirow{2}{*}{ Items } & \multicolumn{3}{|c|}{$\mathrm{T} 1$} & \multicolumn{3}{|c|}{$\mathrm{T} 2$} \\
\hline & $\mathrm{M}(\mathrm{T})$ & $\mathrm{M}(\mathrm{S})$ & $\mathrm{M}(\mathrm{D})$ & $\mathrm{M}(\mathrm{T})$ & $\mathrm{M}(\mathrm{S})$ & $\mathrm{M}(\mathrm{D})$ \\
\hline $\begin{array}{l}\text { FTF } \\
\end{array}$ & 8.66 & $3.77^{*}$ & 4.89 & 8.90 & $3.78 *$ & 5.13 \\
\hline Voice calls & 6.96 & 4.70 & 2.23 & 7.56 & 5.00 & 2.79 \\
\hline IM & 7.74 & 5.09 & 2.66 & 7.99 & 5.20 & 2.76 \\
\hline Email & 6.31 & 1.84 & 4.48 & 7.06 & 2.31 & 4.72 \\
\hline Voice \& FTF & 4.17 & 2.55 & 1.63 & 4.20 & 2.72 & 1.48 \\
\hline IM \& FTF & 4.68 & 2.85 & 1.83 & 4.64 & 2.92 & 1.72 \\
\hline IM \& Voice & 4.59 & 3.12 & 1.46 & 5.22 & 3.56 & 1.67 \\
\hline Email \& FTF & 2.76 & 0.92 & 1.84 & 3.09 & 1.07 & 2.02 \\
\hline Email \& voice & 1.81 & 0.77 & 1.04 & 2.66 & 1.27 & 1.38 \\
\hline Email \& IM & 2.08 & 0.91 & 1.17 & 2.87 & 1.36 & 1.51 \\
\hline Note: $* p<.05$. & $\begin{array}{l}\text { T:Tota } \\
\text { D: Diff }\end{array}$ & $\begin{array}{r}\text { S: S } \\
\text { ent-l }\end{array}$ & $\begin{array}{l}\text {-lang } \\
\text { lage }\end{array}$ & $\begin{array}{l}\text { speal } \\
\text { ers }\end{array}$ & & \\
\hline
\end{tabular}

TABLE VII: THE PLACES OF CONTACT PERSONS IN EACH SSN

\begin{tabular}{l|cc|cc}
\hline \hline \multirow{2}{*}{ SSNs } & \multicolumn{2}{c|}{ T1 } & \multicolumn{2}{c}{ T2 } \\
& In Japan & Oversea & In Japan & Oversea \\
\hline Voice calls & $62.9 \%$ & $37.1 \%$ & $68.8 \%$ & $30.2 \%$ \\
IM & $57.6 \%$ & $42.4 \%$ & $67.9 \%$ & $32.1 \%$ \\
Email & $80.5 \%$ & $19.5 \%$ & $54.0 \%$ & $46.0 \%$ \\
\hline \hline
\end{tabular}

From Table VI, we found that (a) SSNs via FTF were still the largest among the four SSNs in both T1 and T2, among which ISs communicated with more different-language speakers than same-language speakers; (b) the number of SSNs through voice calls and IM were almost the same, among which they communicated with more same-language speakers than through FTF; (c) the number of SSNs through email was the smallest, but ISs did send emails to more different-language speakers than same-language speakers. Additionally, compared to T1, the number of same-language speakers through FTF in T2 became larger, but others seemed to be the same. Furthermore, we also confirmed whether ISs' history of stay in Japan had any effects on their SSN formations; the results showed that only the number of crossgender/different-language speakers through email had become smaller slightly $(\beta=-.20, p<.10)$. These results indicated that ISs' SSN formation did not change easily.

Next, when we looked at each SSN's relationship (also see Table VI), we found that nearly $60 \%$ of contact persons through IM (T1: 4.68/7.74; T2: 4.64/7.99) and over half of the contact persons through voice calls (T1: 4.17/6.96; T2: 4.20/7.56) were those they met in person. Additionally, nearly $60 \%$ of the same-language speakers through IM (T1: 2.85/5.09; T2: 2.92/5.20) and over half through voice calls (T1: 2.55/4.70; T2: 2.72/5.00) were also listed in the SSN through FTF. Furthermore, nearly $70 \%$ of the contact samelanguage speakers through IM were also those through voice calls (T1: 3.12/5.09; T2: 3.56/5.20). On the other hand, 40\% of the contact persons (T1: 2.76/6.31; T2: 3.09/7.96), half of the contact same-language speakers (T1: 0.92/1.84; T2: $1.07 / 2.31$ ) and $40 \%$ of the different-language speakers (T1: 1.84/4.48; T2: 2.02/4.72) through email were those that were listed in the SSNs through FTF. Furthermore, as Table VII indicates, over half of the contact persons through voice calls, IM and email were in Japan.

The study also analyzed whether their social networks in Japan and their home countries originally influenced their SSN formation or not. Regarding the number of "Japanese friends/acquaintances with whom I have frequent contact in Japan," 5.1\% answered "None," 36.4\% answered "Less than 5 persons," 33.3\% answered "5-10 persons," and 12.1\% answered “ $10-15$ persons.” In other words, nearly $80 \%$ of the ISs had fewer than 10 Japanese friends/acquaintances that could be frequently contacted. Then, the Multiple Regression Analysis was conducted, adding the number of SSNs as dependent variables, gender and the number of Japanese friends/acquaintances as independent variables. The results showed that the number of Japanese friends/acquaintances had significant effects on decreasing their communication with same-language speakers through FTF $(\beta=-.41, p<.05)$ and increased their communication with different-language speakers through FTF $(\beta=.44, p<.05)$, but no similar effects were detected in voice calls, IM, or email.

\section{Relationship between Social Skills and SSNs}

In order to investigate the causal relationship between ISs' social skills and SSNs formed through FTF, voice calls, IM and emails, this study conducted an analysis of cross-lagged effect model (Fig. 2). SSNs here refer to the number of different-language speakers, the total contact frequency and their importance to the ISs. This study conducted Analysis of Multi-population for gender to clarify gender differences. For each model, this study confirmed their Goodness of Fit Index (GFI), a Comparative Fit Index (CFI), and a Root Mean Square Error of Approximation (RMSEA). Generally, a model is described as excellent if the model's GFI and CFI are higher than .90, and the RMSEA is lower than .05. In this study, all model indices had extremely good indices (GFI $=.97-1.000$, a CFI=.97-1.000, and a RMSEA =.00-.06). Table VIII shows the results for path $a$ and path $R a$.

From Table VIII, it was found that (a) male ISs' social skills had no effects on their SSNs except for their contact frequency with same-gender/different-language speakers through voice calls; (b) female ISs' social skills had negative effects on their SSNs through FTF and IM, and positive effects on their SSNs through email, but no effects were detected among their SSNs via voice calls; (c) for female ISs, the importance of cross-gender/different-language speakers had slightly negative effects on their social skill, but no effects for SSNs on social skills were found for male ISs.

\section{E. Relationship between SSNs and Maladaptation, Social Skills and Maladaptation}

Prior to analyzing the three variables' causal relationship, it is necessary to confirm which factor(s) influence their maladaptation in T2. A Multiple Regression Analysis was conducted, adding their maladaptation in T2 as dependent variable, gender, age, their history of staying in Japan, their Japanese and English proficiency, the number of contact Japanese friends/acquaintances, the number of contact friends/acquaintances from the same country in Japan and the number of contact friends/acquaintances living in their home country with, and maladaptation in $\mathrm{T} 1$, as independent 
variables. As a result, maladaptation in T1 and the number of contact friends/acquaintances living in their home country had significant effects (the former: $\beta=.56, p<.001$; the later: $\beta=-.22, p<.05$ ), and gender had slightly significant effects $(\beta=-1.67, p<.10){ }^{4}$ The adjusted $\mathrm{R}^{2}$ for the model was .34, $p<.001$.

TABLE VIII: RESULTS ABOUT PATH A \& RA

\begin{tabular}{|c|c|c|c|}
\hline \multirow{2}{*}{ SSNs } & Male & \multicolumn{2}{|c|}{ Female } \\
\hline & a $\quad R a$ & A & $R a$ \\
\hline \multicolumn{4}{|l|}{ FTF } \\
\hline Number of DLS & & $-.31^{*}$ & \\
\hline Number of SG \& DLS & & $-.24 *$ & \\
\hline Frequency of DLS & & $-.23^{*}$ & \\
\hline Frequency of SG \& DLS & & $-.21^{*}$ & \\
\hline Importance of DLS & & $-.33^{*}$ & \\
\hline Importance of CG \& DLS & & $-.25 \dagger$ & $-.07 \dagger$ \\
\hline \multicolumn{4}{|l|}{ Voice calls } \\
\hline Frequency of SG\& DLS & $.25^{*}$ & & \\
\hline \multicolumn{4}{|l|}{$\mathrm{IM}$} \\
\hline Number of SG \& DLS & & $-.28 *$ & \\
\hline Importance of SG \& DLS & & $-.27 \dagger$ & \\
\hline \multicolumn{4}{|l|}{ Email } \\
\hline Number of CG \& DLS & & $.29 *$ & \\
\hline Frequency of DLS & & $.24 \dagger$ & \\
\hline Frequency of CG \& DLS & & $.23 \dagger$ & \\
\hline Importance of CG \& DLS & & $.22 \dagger$ & \\
\hline $\begin{array}{l}\text { Note: } \dagger p<.10 ;{ }^{*} p<.05 \text {. } \\
\text { DLS: different-langu } \\
\text { SG: same gender; }\end{array}$ & akers; & gender & \\
\hline
\end{tabular}

TABLE IX: RESULTS ABOUT PATH B, C AND PATH RB, RC

\begin{tabular}{|c|c|c|c|c|}
\hline \multirow{2}{*}{ SSNs } & \multicolumn{2}{|c|}{ Male } & \multicolumn{2}{|c|}{ Female } \\
\hline & $\mathrm{b} / \mathrm{Rb}$ & $\mathrm{c} / \mathrm{Rc}$ & $\mathrm{b} / R \mathrm{~b}$ & $\mathrm{c} / \mathrm{Rc}$ \\
\hline \multicolumn{5}{|l|}{ FTF } \\
\hline Number of DLS & $-.29 *$ & $-.06 * *$ & & \\
\hline Number of SG \& DLS & $-.21 \dagger$ & $-.06 *$ & $.21 \dagger-.30 *$ & \\
\hline Number of CG \& DLS & $-.23 *$ & $-.06 *$ & $-.34 * *$ & \\
\hline Frequency of DLS & $-.20 \dagger$ & $-.06 *$ & & \\
\hline Frequency of SG \& DLS & & $-.06^{*}$ & $-.28 *$ & \\
\hline Frequency of CG \& DLS & & $-.06 *$ & $-.33 *$ & \\
\hline Importance of DLS & $-.25 *$ & $-.06 *$ & & \\
\hline Importance of SG \& DLS & & $-.06 *$ & $-.36 * *$ & \\
\hline Importance of CG \& DLS & $-.18 \dagger$ & $-.06 *$ & $-.32 *$ & \\
\hline \multicolumn{5}{|l|}{ Email } \\
\hline Importance of DLS & $.19 \dagger$ & $-.06 * *$ & & \\
\hline Importance of CG \& DLS & $.24^{*}$ & $-.06 *$ & & \\
\hline \multicolumn{5}{|c|}{$\begin{array}{l}\text { Note: } \dagger p<.10 ;{ }^{*} p<.05 ;{ }^{*} p<.01 \\
\text { DLS: different-language speakers; }\end{array}$} \\
\hline SG: same gender; & & CG: cros & gender & \\
\hline
\end{tabular}

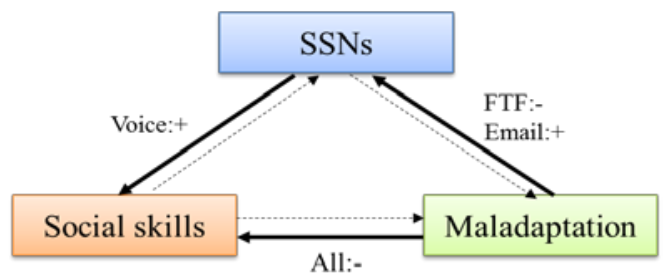

Fig. 4. Relationship between 3 variables for male ISs.

4 Since "gender" is nominal scale, this study coded male as " 1 ” and female as " 2 ” when conducting analysis.

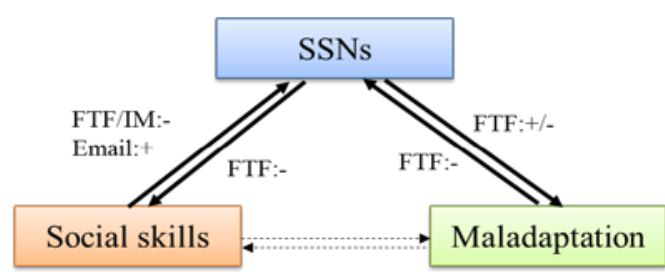

Fig. 5. Relationship between 3 variables for female ISs.

Next, this study analyzed the relationship between ISs' SSNs, maladaptation, controlling for the effects of social skills as Fig. 3 shows. Table IX shows the effects that were significant or slightly significant. From the results, we found that (a) male ISs' SSNs had no effects on their maladaptation whereas female ISs' SSNs via FTF had significant effects on decreasing their maladaptation except for the number of same-gender/different-language speakers; (b) male and female ISs' maladaptation influenced their communication with different-language speakers via FTF interactions. In other words, ISs with lower levels of maladaptation were able to communicate with different-language speakers, particularly with cross-gender; (c) male ISs with higher levels of maladaptation tended to communicate with different- language speakers through emails, but no similar results were detected among female ISs; (d) no effects for social skills on maladaptation could be found, but male ISs with lower levels of maladaptation were able to improve their social skills.

Based on the above results, the relationship between social skills, SSNs and maladaptation for male and female ISs could be described as Fig. 4 and Fig. 5.

\section{DISCUSSION}

There were three purposes of this study. The first was to examine the effects of ISs' SSNs on maladaptation, including the gender differences. As a result, Hypothesis 1 was fully supported in case of FTF interactions. Previous studies [6]-[8] suggested that ISs' SSNs including more different- language speakers, especially Japanese native speakers, would be helpful in decreasing their maladaptation; this study indicated that this could only be found for female ISs. Note that previous studies did not examine the interactions of gender differences and communication media.

One of the reasons for the differences between FTF and communication media could be explained as follows. As Table VI shows, ISs mainly communicated with differentlanguage speakers through FTF, while they mostly made voice calls and sent text messages through IM to the samelanguage speakers. This characteristic of their "selective" usage might not change easily, making it difficult for them to use with different-language speakers. Additionally, although ISs also mainly sent emails to different speakers, nearly half of the contact persons were not living in Japan in T2 (see Table VII). As previous studies indicated, young generations send text messages through IM to form "strong ties" with those they often meet, such as friends, lovers, and families, while sending emails to form "weak ties" and formal relationships [13]. Therefore, it is reasonable to believe that the lack of physical distance and intimacy through email communication would be the main reason for no effects on 
decreasing ISs' maladaptation.

Regarding the configurations of ISs' SSNs, the average number in the 1990s was 7.76 through FTF interactions [6], while the average number was 6.80 when using regular cell phones to make voice calls [9]. This study indicated that the average number of ISs' SSNs was from 6.31 to 7.99 , among which those via FTF were still the largest. These results suggest that ISs' SSNs might not easily change due to the use of communication media.

The second purpose of this study was to demonstrate the effects of ISs' adaptation on their SSNs. As indicated in Hypothesis 2, it is supposed that ISs with lower levels of maladaptation would be able to communicate with differentlanguage speakers through FTF and communication media usage, while ISs with higher levels of maladaptation might tend to communicate with same-language speakers more, regardless of communication media, among which gender differences will be found. As the results showed, male and female ISs with lower levels of maladaptation were able to communicate with different-language speakers through FTF interactions, but no effects for voice calls or IM usage were found. These results suggested that decreasing ISs' daily life/ interpersonal stress and loneliness would be effective to promote their intercultural communication with differentlanguage speakers through FTF interactions, but media usage such as voice calls and IM cannot be expected to have the same effects since ISs use them mostly to communicate with same-language speakers. On the other hand, male ISs with higher levels of maladaptation communicated with more different-language speakers through emails, which was out of our assumption, but no similar effects were detected among female ISs. In this sense, Hypothesis 2 was partly supported. As mentioned earlier, young generations send email to their academic advisors/faculty members for formal relationships, which might be important to their lives; however, the purpose for sending emails to advisors/faculty members might be for their research or study in Japan, which would increase ISs' stress in turn. Since email usage had no effects among female ISs, and the level of maladaptation did not show any differences due to gender, further research about the detailed usage might be necessary.

The third purpose of the present study was to examine social skills' effects on ISs' SSNs and adaptation. The results suggested that male ISs' social skills had no effects on their SSNs, while female ISs' social skills had negative effects on their SSNs through FTF and IM and positive effects through email. Furthermore, social skills had no direct effects on ISs' adaptation for both male and female ISs, but male ISs' adaptation influenced their social skills significantly negatively. The items for social skills in this study were not only for intercultural communication, but focused on how to get along well with others in general, which might exclude female ISs' intercultural contacts through FTF and IM in turn. Since female people tend to ask for help from male people [28], female ISs with higher levels of social skills tend to form larger SSNs with cross-gender/different-language people through email, it is necessary to consider the interactions between social skills and ways for communication when examining the relationship between social skills and SSNs.
In addition, since different media usages have different effects on users due to culture differences [33], [34], which also relates to their social identity and perception of in-group/out- group members [35], it is necessary to conduct comparative studies to include these points in the future.

\section{A. Limitations and Future Research}

It is necessary to note the generality of the findings in the present study. All the analyzed ISs were from national universities in the Kanto Region, Japan, and both T1 and T2 in this study were before final exams and before long-term holidays. However, the results indicated there were almost no changes among ISs' SSNs in both times. The main reason for examining ISs' SSNs in the last six months was to allow ISs to form stable relationships with others considering their stay period and to compare to previous studies. In addition, different-language speakers in this study included Japanese native speakers and ISs from other countries/regions. From the viewpoint of intercultural contact, this study provided some important implications about the relationship between ISs' social skills on their SSNs and adaptation; however, it is desirable to divide Japanese native speakers into other ISs in more detail in the future to detect whether there are any similarities/differences compared to this study.

\section{CONCLUSION}

As already described, this study has indicated that: (a) female ISs' SSNs with different-language speakers through FTF are helpful in decreasing their maladaptation; (b) male and female ISs with lower levels of maladaptation are able to communicate with different-language speakers through FTF interactions; and (c) social skills only have positive effects on female ISs' SSNs with cross-gender/different-language speakers via email. From the results, it is suggested that improving female ISs' social skills will be beneficial in decreasing their maladaptation through the mediation of their SSNs with cross-gender/different-language speakers through FTF interactions; meanwhile, it is necessary to find other methods to help male ISs decrease their maladaptation. The findings of this study provided implications for discussing the interactions between gender and communication media usage when examining the relationship between intercultural communication and adaptation.

\section{ACKNOWLEDGMENT}

The author would like to thank all the professors at Tokyo Institute of Technology, and Prof. Tatsuya Horita from Tohoku University for their cooperation in this survey, and all the students who answered the questionnaire survey.

\section{REFERENCES}

[1] Ministry of Education, Culture, Sports, Science and Technology (MEXT). (2008). The outline of Japan's system for international students (Wagakuni no ryugakuseiseido no gaiyo). [Online]. Available: http://www.mext.go.jp/a_menu/koutou/ryugaku/081210.pdf

[2] Japan Student Services Organization (JASSO). (2016). Result of an annual survey of international students in Japan 2015. [Online]. Available:

http://www.jasso.go.jp/about/statistics/intl_student_e/2015/_icsFiles/ afieldfile/2016/03/14/data15.pdf 
[3] T. Tanaka and M. Yokoda, "International students' living style and stress in Japan,” Gakusei Soudan Kenkyu, vol. 14, pp. 51-59, 1992.

[4] Y. Ryan, "The support needs of international doctoral students in a Japanese university: A research survey," Bulletin of the International Center Shizuoka University, vol. 8, pp. 81-102, March 2014.

[5] J. Iwao and S. Hagiwara, Niho de Manabu Ryugakusei: Shaykai Shinrigakuteki Bunseki (International Students Study in Japan: Analysis from the Perspective of Social Psychology), Keiso Shobo, 1988.

[6] T. Tanaka, J. Takai, H. Minami, and T. Fujihara, "A study on the adjustment of international students in Japan (2): Implications of social network formation on newly arrived students," Studies in culture and the Humanities at Hiroshima University, vol. 14, pp. 95-113, March 1992.

[7] T. Tanaka, J. Takai, H. Minami, and T. Fujihara, "A study on the adjustment of international students in Japan (3): Implications of social network formation during half year on newly arrived students," Bulletin of International Center at Hiroshima University (Hiroshimadaigaku Ryugakuseisenta Kiyo), vol. 1, pp.77-95. March 1992.

[8] T. Tanaka, K. Hatanaka, and Y. Okunishi, "Behaviors that Japanese students expect from their international friends: Analyzing perspectives of cross-cultural social skills and formation of interpersonal relationships,” Multicultural Relations, vol. 8, pp. 35-54, 2011.

[9] S. M. Kim, "The relationship between social network and cellularphone use for international students in Japan," The Bulletin of the Institute of Socio-Information and Communication Studies, vol. 65, pp. 363-394, March 2003.

[10] S. Y. Ye and M. Murota, "Influence of international students' communication media usage on their adaptation situation to daily lives in Japan: Focusing on cell phone and computer usage," Journal of Socio-Informatics, vol. 3, no. 1, pp. 1-15, September 2014.

[11] K. V. Cleemput, "'I'll see you on IM, text, or call you': A social network approach of adolescents' use of communication media," Bulletin of Science, Technology \& Society, vol. 30, no. 2, pp. 75-85, April 2010.

[12] H. Kim, G. J. Kim, H. W. Park, and R. E. Rice, "Configurations of relationships in different media: FTF, email, instant messenger, mobile phone, and SMS," Journal of Computer-Mediated Communication, vol. 12, no. 4, pp. 1183-1207, July 2007.

[13] A. Lenhart, P. Hitlin, and M. Madden. (2005). Teens and technology. [Online]. Available: http://www.pewinternet.org/2005/07/27/teens-and-technology/

[14] S. Y. Ye, A. Toshimori, and T. Horita. (Sept. 2016). Relationship between college students' smartphone dependency, social networks and loneliness, considering the personality traits' effects. The Society of Socio-Informatics (SSI) 2016 National Annual Meeting, III-1.

[15] T. Igarashi, "The effect of social skills on loneliness through mediation of CMC social networks," Japanese Journal of Social Psychology, vol. 17, no. 2, pp. 97-108, January 2002.

[16] T. Tanaka, J. Takai, T. Kohyama, C. Muranaka, and T. Fujihara, "A study on the adjustment of international students in Japan (1): A factor analysis of cross-cultural adjustment scale," Studies in Culture and the Humanities at Hiroshima University, vol. III, no. 14, pp. 77-94, March 1992.

[17] T. Tanaka, "Cross-cultural adjustment and social skills," Journal of Japanese Language Teaching, vol. 146, pp. 61-75, August 2010.

[18] S. Y. Ye and M. Murota, "The structure of international students' intimate social networks via different communication media," The Society of Socio-Informatics (SSI) 2015 National Annual Meeting, pp. 44-49, Sept. 2015.

[19] Y. H. Jou, "An examination of a causal model for received support and adjustment of Chinese students in Japan," The Japanese Journal of Psychology, vol. 66, no. 1, pp. 33-40, 1995.

[20] B. M. Mulvaney. (1994). Gender differences in communication: An intercultural experience. [Online]. Available: http://feminism.eserver.org/gender/cyberspace/gender-differences.txt
[21] T. Pierce, "Social anxiety and technology: Face-to-face communication versus technological communication among teens," Computers in Human Behavior, vol. 25, no. 6, pp. 1367-1372, November 2009.

[22] T. Igarashi, J. Takai, and T. Yoshida, "Gender difference in social network development via mobile phone text messages: A longitudinal study,” Journal of Social and Personal Relationships, vol. 22, no. 5, pp. 691-713, October 2005.

[23] G. Mesch, I. Talmud, and A. Quan-Haase, "Instant messaging social networks: Individual, relational, and cultural characteristics," Journal of Social and Personal Relationships, vol. 19, no. 6, pp. 736-759, September 2012.

[24] K. M. Cramer and K. A. Neyedley, "Sex differences in loneliness: The role of masculinity and femininity," Sex Roles, vol. 38, no. 718, pp. 645-653, 1998.

[25] A. N. Joindon, "Self-disclosure in computer-mediated communication: The role of self-awareness and visual anonymity," European Journal of Social Psychology, vol. 31, pp. 177-182, March/April 2001.

[26] M. Argyle, The Psychology of Happiness, 2nd ed. Routledge, 2001.

[27] R. F. Rohrlich and J. Martin, "Host country and reentry adjustment of student sojourners," International Journal of Intercultural Relations, vol. 15, no. 2, pp. 163-182, December 1991.

[28] A. Nadler, S. Maler, and A. Frideman, "Effects of helper's sex, subjects' androgyny, and self-evaluation on males' and females' willingness to seek and receive help," Sex Roles, vol. 10, no. 5, pp. 327-339, June 1984.

[29] X. Mao, "Applicability of the social skill scale, KiSS-18 to Chinese teenagers,” Japanese Journal of Interpersonal and Social Psychology, vol. 5, pp. 85-91, 2005.

[30] S. E. Finkel, Causal analysis with panel data. Series (Quantitative Applications in the Social Sciences Series), Sage Publication, Inc: Thousand Oaks, CA. 1995.

[31] R. Ando, A. Sakamoto, K. Kobayashi, M. Kashibuchi, and F. Kimura, "Effects of the Internet use on life satisfaction and social efficacy: A panel study of male students in a vocational college of information technology,” The Japanese Journal of Personality, vol. 13, no. 1, pp 21-33, September 2004.

[32] S. Y. Ye, A. Toshimori, and T. Horita, "The causal relationships between college students' media/social media usage and Internet literacy, controlling for the effects of social skills and gender differences on them,” Japan Journal of Educational Technology, vol. 40, no. 3, pp. 165-174.

[33] G. M. Chen, "The impact of new media on intercultural communication in global context,” China Media Research, vol. 8, no. 2, pp. 1-10, April 2012.

[34] R. Shuter, "Intercultural new media studies: The next frontier in intercultural communication,” Journal of Intercultural Communication Research, vol. 41, no. 3, pp. 219-237, November 2012.

[35] A. Y. Chiou, "Which cultural group I love depends on how I feel about my identities: The moderating effect of blendedness on the priming of cultural in-group love in undergraduate Asian-American biculturals," International Journal of intercultural Relations, vol. 54, pp. 87-96, September 2016

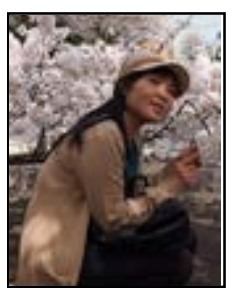

Shaoyu Ye was born in Canton, China, and is efficien in Chinese (both Cantonese and Mandarin), Japanese and English.

She received her Ph.D (in Philosophy) from Tokyo Institute of Technology (2015); master of socia psychology from Ochanomizu University (Japan) (2010); master of Japanese language and literature from Shanghai Institute of Studies University (2006), and a bachelor of Japanese language and literature from South China Normal University (2003).

Dr. Ye is a pioneer researcher specializing in media usage's effects on interpersonal communication especially intercultural communication and social support networks. She was also a research fellow of the Japan society for the Promotion of Science (JSPS) from 2014-15 (DC2 \& PD).

Dr. Ye is currently serving as an assistant professor at the Faculty of Library, Information and Media Science, University of Tsukuba in Japan. 